\title{
LMB-89 Regimen
}

National Cancer Institute

\section{Source}

National Cancer Institute. LMB-89 Regimen. NCI Thesaurus. Code C67195.

A regimen containing high-dose cyclophosphamide, vincristine, doxorubicin and

prednisone, used as a treatment for localized, childhood non-Hodgkin lymphoma and also for childhood L3 leukemia. 